\title{
EPISTEMOLOGIA(S) DA EDUCAÇÃO MUSICAL ESCOLAR: UMA ANÁLISE DA PROPOSTA FORMATIVA "MULHERES NA MÚSICA"
}

\author{
Epistemology(ies) of school music education: \\ an analysis on the "Women in Music" \\ formative proposal
}

\author{
Epistemología(s) de la educación musical \\ escolar: un análisis de la propuesta formativa \\ "Mujeres en la Música"
}

Thaís Lobosque Aquino

Universidade Federal de Goiás tlobosque@ufg.br

\begin{abstract}
Resumo: Este artigo objetiva examinar a(s) epistemologia(s) da educação musical escolar, por meio da análise da proposta formativa "Mulheres na Música" desenvolvida no primeiro semestre de 2017 , envolvendo 127 participantes diretos. Tal proposta demonstrou três possiveis formas de inclusão da música no contexto escolar: como atividade no contraturno, como projeto de extensão e como disciplina curricular obrigatória. Em cada uma delas, foi evidenciada a vida e a obra de uma musicista, respectivamente, Rita Lee, Nannerl Mozart e Chiquinha Gonzaga. A fim de analisar as três ações que compõem a proposta, foram feitas pesquisa bibliográfica e de campo. A primeira abrange o estudo de autores que problematizam a categoria de saber sensivel (Aquino, 2018a, 2021; Duarte Júnior, 2000). A pesquisa empírica se baseou nos princípios da etnografia e da pesquisa-ação (Angrosino, 2009; Ghedin; Franco, 2011; Oliveira, A., 2013), e os dados colhidos foram sistematizados em diários de campo, planos de aula reflexivos e relatos de experiência. O exame desses documentos evidencia a importância em combater o processo de invizibilização das produções femininas no campo musical, bem como demonstra avanços e pontos de embaraço do trabalho pedagógico com saberes musicais sensiveis no ambiente escolar.
\end{abstract}

Palavras-chave: Epistemologia. Saber sensivel. Educação básica. Música na escola. Mulheres na música.

\begin{abstract}
This article aims to examine the epistemology(ies) of school music education, by the analysis of a formative proposal named "Women in Music", which was developed on the first semester of 2017, involving 127 direct participants. The proposal showed three possible ways to include music in the school context: as an activity during the out of school hours, as an extension project and as a mandatory curricular subject. In each one of them, the life and the work of a female musician was highlighted, such as, respectively, Rita Lee, Nannerl Mozart and Chiquinha Gonzaga. In order to analyze the three actions that compose the proposal, bibliographic and field research were made. The bibliographic research covers the study of several authors who discuss the subject of sensible knowledge (Aquino, 2018a, 2021; Duarte Júnior, 2000). The empirical research was based on the principles of ethnography and research-action (Angrosino, 2009; Ghedin; Franco, 2011; Oliveira, A., 2013), and the collected data was systematized in field diaries, reflexive lesson plans and experience reports. The examination of these documents shows the importance of the struggle against the invisibilization of female productions in the music field, as well as demonstrates advances and embarrassment points of the pedagogical work with music sensible knowledges inside the school environment.
\end{abstract}

Keywords: Epistemology. Sensible knowledge. Basic education. Music in schools. Women in music.

Resumen: Este artículo tiene como objetivo examinar la (s) epistemología (s) de la educación musical escolar, a través del análisis de la propuesta formativa "Mujeres en la Música" desarrollada en el primer semestre de 2017, con 127 participantes directos. Esta propuesta demostró tres posibles formas de incluir la música en el contexto escolar: como actividad en el contraturno escolar, como proyecto de extensión y como asignatura obligatoria del plan de estudios. En cada uno de ellos se destacó la vida y obra de una música, Rita Lee, Nannerl Mozart y Chiquinha Gonzaga. Para analizar las tres acciones que componen la propuesta se realizó una investigación bibliográfica y de campo. El primero 
abarca el estudio de autores que problematizan la categoría de saber sensible (Aquino, 2018a, 2021; Duarte Júnior, 2000). La investigación empírica se basó en los principios de la etnografía y la investigación-acción (Angrosino, 2009; Ghedin; Franco, 2011; Oliveira, A., 2013), y los datos recolectados fueron sistematizados en diarios de campo, planes de lecciones reflexivas e informes de experiencias. El examen de estos documentos destaca la importancia de combatir el proceso de invisibilización de las producciones femeninas en el ámbito musical, así como evidenciar avances y retos en el trabajo pedagógico con saberes musicales sensibles en el ámbito escolar.

Palabras clave: Epistemología. Saber sensible. Educación básica. Música en la escuela. Mujeres en la musica.

\section{APONTAMENTOS INICIAIS}

O movimento pela aprovação da Lei $n^{\circ} 11.769 / 2008$ (Brasil, 2008), que tornou a música conteúdo obrigatório do componente curricular Arte na educação básica, impulsionou inúmeros debates e práticas acerca de possibilidades para o ensino de música nas escolas brasileiras. Mesmo com a recente substituição desse dispositivo legal pela Lei $\mathrm{n}^{\circ}$ 13.278/2016 (Brasil, 2016), ${ }^{1}$ que, além da música, inclui as artes visuais, a dança e o teatro como linguagens da Arte, as discussões continuam efervescentes, de modo a viabilizar a democratização dos saberes musicais nas escolas de educação básica.

Há que se destacar a existência de propostas nessa direção com diferentes matizes, seja pelo contexto abordado, seja pela etapa/modalidade da educação básica enfocada, seja pela metodologia trabalhada, seja pelos conteúdos musicais evidenciados (Andraus, 2008; Aquino, 2018b; Beineke, 2015; Marques, 2019; Oliveira, A. A., 2019; Sebben; Subtil, 2010; Wolffenbüttel, 2010).

De forma geral, tais propostas revelam a intenção de educadores musicais em propiciar formação em música para bebês, crianças, jovens e/ou adultos brasileiros, entendendo a educação musical como campo do saber com modos de operar peculiares. Compreendê-la como campo do saber significa pensá-la e praticá-la conforme suas especificidades e as múltiplas relações que estabelece com outros campos do saber no ambiente escolar.

Para esmiuçar afirmações como essa, vêm ganhando destaque estudos comprometidos em problematizar a epistemologia ou as epistemologias da educação musical escolar. Este artigo vem, justamente, somar esforços no sentido de examinar a(s) epistemologia(s) da educação musical escolar, tendo como base a análise de três ações formativas em torno do tema "Mulheres na Música" . ${ }^{2}$ As referidas ações envolveram uma instituição de ensino superior (IES) e uma escola de educação básica, e contaram com o trabalho em equipe

\footnotetext{
1 Tanto a Lei $n$ o 11.769/2008 quanto a Lei no 13.278/2016 correspondem a modificações no parágrafo sexto do artigo 26 da Lei de Diretrizes e Bases da Educação Nacional (LDB), Lei no 9.394/1996 (Brasil, 1996).

2 Várias pessoas comprometidas com o ensino de música foram importantes para a consecução desta proposta: professoras, estagiárias/os, crianças e membras/os das duas instituições envolvidas (Emac/UFG e Cepae/UFG). De forma especial, evidencio a atuação inspiradora da professora de música do Cepae/UFG, Telma de Oliveira Ferreira, e a parceria na disciplina de Estágio Supervisionado 1 de minha colega orientadora de estágio da Emac/ UFG, Ruth Sara de Oliveira Moreira.
} 
de professoras orientadoras, professora supervisora, estagiários do curso de Música-Licenciatura e crianças do ensino fundamental.

Para alcançar o objetivo explicitado acima, foram realizadas pesquisas bibliográfica e de campo. A primeira correspondeu à leitura e ao estudo de fontes que tematizam direta ou indiretamente o conceito de saber musical sensivel (Aquino, 2018a, 2021; Duarte Júnior, 2000). A pesquisa empírica se valeu dos aportes da etnografia e da pesquisa-ação (Angrosino, 2009; Ghedin; Franco, 2011; Oliveira, A., 2013) tanto para a coleta quanto para o exame dos dados colhidos junto às ações formativas ora investigadas.

Em termos estruturais, o texto se desenvolve em três partes. Na primeira, são discutidos construtos teóricos relacionados à(s) epistemologia(s) da educação musical escolar, em especial à categoria de saber sensivel. Na segunda, descreve-se a proposta formativa "Mulheres na Música". Finalmente, na terceira parte, procede-se à análise da proposta em articulação com a noção de saber musical sensivel, de modo a perceber possiveis contribuições e pontos de embaraço dessa articulação para o trabalho pedagógico-musical escolar.

\section{EPISTEMOLOGIA(S) DA EDUCAÇÃO MUSICAL ESCOLAR E SABER MUSICAL SENSÍVEL}

Aquino (2018a, 2021) investiga a epistemologia da educação musical escolar, apoiada no entendimento do saber musical como saber sensivel. O termo "saber" é empregado pela autora de forma deliberada em substituição a "conhecimento", expressão comumente utilizada quando se quer analisar algo em sua dimensão científica. Assim, "saber" remete a uma significação mais ampla: um conjunto de conteúdos, experiências, habilidades e valores adquiridos em processos pedagógicos mais ou menos formais que mobilizam corpo e mente, princípios éticos e conceitos, razão e emoção, teorias e práticas. Portanto, tratar a música como saber é evidenciar seu potencial formativo para impulsionar o indivíduo globalmente.

Porém, o saber musical não é apenas saber, é saber sensível. Sobre a expressão, Duarte Júnior (2000, p. 14) afirma: "Sem dúvida, há um saber sensivel, inelutável, primitivo, fundador de todos os demais conhecimentos, por mais abstratos que estes sejam; um saber direto, corporal, anterior às representações simbólicas que permitem os nossos processos de raciocínio e reflexão." Mesmo considerando a importância do autor, bem como a influência dos seus construtos teóricos para o campo da arte no Brasil, há que se deixar claro que sua definição se difere radicalmente daquela defendida por Aquino (2018a, 2021) e reafirmada neste trabalho.

Nesse âmbito, o saber musical é compreendido como saber sensivel, fundamentalmente, por sua tendência articuladora. Isso quer dizer que não se trata, apenas, de um saber inicial, anterior à abstração e, por isso, diferente de processos lógico-intelectivos. O saber sensivel inclui tais processos justamente por sua propensão para articular aspectos da realidade apreendidos de forma dicotomizada. Assim, é saber sensivel aquele capaz de colocar em tensão intelecto e corporeidade, razão e emoção, experiências e conceitos, ética 
e sensibilidade, dentre tantas outras oposições características dos modos de operar ocidentais, tais como masculino e feminino, branco(a) e negro(a), dominante e dominado(a), para citar algumas.

A propósito, o uso do complemento "sensivel" acontece como recurso linguístico para fazer frente aos saberes hegemônicos dos currículos das escolas de educação básica: saberes tradicionalmente reduzidos ao intelectivo, alheios à sensibilidade e voltados, sobretudo, à construção do pensamento abstrato. Saberes, também, que comumente privilegiam construtos produzidos e legitimados por sujeitos masculinos, brancos e europeus. Portanto, falar em saber sensivel é reforçar a importância da escola e, mais especificamente, da educação musical escolar na finalidade de articular os fundamentos somáticos, éticos, cognitivos e emocionais dos saberes no decurso do processo educativo. É, além disso, corroborar a necessidade de a educação musical escolar propiciar o trabalho didático com produtos, conceitos e vivências de minorias historicamente alijadas dos processos culturais e educacionais.

Sobre o saber musical sensivel, Aquino (2021, p. 207) afirma que ele faz parte de um campo dinâmico de relações em que se articulam fundamentos, dimensões e perspectivas:

Os fundamentos dizem respeito aos eixos medulares que constituem os alicerces desse saber. As dimensões, aos seus aspectos artísticos, filosóficos e científicos, uma vez que a música é uma linguagem da arte e pode ser elaborada filosófica e/ou cientificamente, embora não seja stricto sensu nem ciência, nem filosofia. As perspectivas compreendem as articulações que o saber musical estabelece com outras vias compreensivas, com outros campos do saber.

A partir das afirmações da autora, é possivel inferir que: i) as perspectivas correspondem às relações do saber musical com saberes dos diversos campos do currículo escolar; ii) as dimensões dizem respeito à possibilidade de se elaborar os saberes musicais filosófica, cientifica e/ou artisticamente, sem perder de vista o fato de a música ser uma linguagem da arte; iii) os fundamentos são os alicerces sobre os quais se edifica o trabalho pedagógico-musical.

A autora aponta quatro fundamentos: ético, cognitivo, emocional e somático. O fundamento ético se baseia na premissa de que não há educação musical escolar desvinculada de valores. Logo, o saber musical sensível está embebido em ética. O fundamento cognitivo coloca em evidência os conceitos e modos de operar musicais. O emocional demonstra que o saber musical sensivel é atravessado pela emoção estética, um modo inteligente de elaborar fantasia, imaginação e criatividade. Por fim, e não menos importante, o fundamento somático: é pelo corpo que se dá a internalização ativa e a externalização sonora dos saberes musicais.

Em sintese, trabalhar com o saber musical sensivel no ambiente escolar pressupõe o compromisso com o desenvolvimento integral dos alunos em termos éticos, cognitivos, emocionais e somáticos, levando-se em consideração, 
ainda, as múltiplas relações que tal saber estabelece com outras vias compreensivas humanas. Acrescente-se às colocações da autora que, para o trabalho pedagógico-musical escolar, é primordial ponderar sobre a seleção do repertório. Afinal, a escolha por determinado artefato musical representa não apenas uma resposta que atenda às peculiaridades do processo educativo em termos de finalidades, conteúdos e procedimentos, mas também a materialização de desideratos ético-políticos que sustentam esse processo e se entrelaçam com ele.

As afirmações feitas no parágrafo anterior tomam parte no complexo mosaico de temáticas que compõem a epistemologia da educação musical escolar. O uso dessa expressão no singular corresponde à necessidade de salientar seu caráter categorial, assim como faz Aquino (2021). Todavia, quando os processos de educação musical se materializam nas escolas, o que se percebe é uma multiplicidade de epistemologias da educação musical escolar ou, até mesmo, epistemologias de educações musicais escolares. Sem desconsiderar a existência de muitas educações musicais e de diversos contextos escolares, opta-se pela expressão epistemologias da educação musical escolar para reforçar a educação musical escolar como um subcampo peculiar de ação e de pesquisa.

Com efeito, as epistemologias da educação musical, que ganham vida nas diversas etapas/modalidades da educação básica, comumente defendem o compromisso com a formação integral dos alunos, por meio de diferentes objetivos, conteúdos, repertórios e metodologias. Existem propostas ancoradas em músicas clássicas, em músicas populares brasileiras e em músicas de culturas populares. Há, ainda, uma considerável variedade procedimental com base nos trabalhos tanto de educadores musicais brasileiros quanto de estrangeiros. Fazendo frente à crescente onda conservadora e autoritária que se levanta sobre o país, vêm ganhando vulto abordagens que contestam processos de dominação contra grupos sociais historicamente marginalizados. Há, por exemplo, epistemologias antirracistas (Aquino, 2020; Marques, 2019; Vieira, 2020), indigenistas (Neves, 2020) e feministas (Aquino, 2018b), para citar algumas.

Neste momento do texto, o foco recai sobre a análise de uma possibilidade para o saber musical sensivel na escola centrada em produções femininas. Em termos mais precisos, busca-se examinar três ações formativas ligadas ao tema "Mulheres na Música" levadas a cabo por professoras e estagiários do curso de Música-Licenciatura da Escola de Música e Artes Cênicas da Universidade Federal de Goiás (Emac/UFG) em parceria com a professora de música do Centro de Ensino e Pesquisa Aplicada à Educação (Cepae), também da UFG, junto a crianças vinculadas à referida instituição escolar.

Com isso, espera-se não só trazer a lume uma alternativa epistemológica para o trabalho pedagógico com saberes musicais sensiveis na escola, como também demonstrar uma proposta comprometida em tornar visíveis produções de mulheres-musicistas, que seguem invisibilizadas nas escolas e no cenário musical contemporâneo. 


\section{Proposta FORMATIVA "MUlHeres NA MÚsicA"}

A proposta centrada no tema "Mulheres na Música"3 aconteceu no primeiro semestre de 2017, envolvendo 127 participantes diretos da Emac/UFG e do Cepae/UFG. O objetivo era promover a interação entre IES e escola de educação básica a partir de três possiveis formas de inclusão da música no contexto escolar: como atividade no contraturno, como projeto de extensão e como disciplina curricular obrigatória.

Naquele semestre, os 14 licenciandos vinculados à disciplina "Estágio Supervisionado 1: Campos de Estágio e Aspectos Ético-Profissionais" do curso de Música-Licenciatura da Emac/UFG atuaram no Festival Bem-Te-Fiz (Universidade Federal de Goiás, 2017a), que aconteceu nas dependências do Cepae/ UFG. O festival foi uma competição entre arranjos instrumentais/vocais/corporais de obras da cantora, musicista e compositora Rita Lee (1947-), cuja biografia fora lançada no ano anterior (Lee, 2016), executados por 23 crianças com idade entre 8 e 12 anos distribuídas em seis grupos, sob orientação dos estagiários e das professoras de música (orientadoras e supervisoras). A final da competição aconteceu no dia 20 de junho de 2017, com a presença de um júri especializado e contou com premiação para os três grupos melhor colocados. ${ }^{4}$

Simultaneamente, os nove estagiários da disciplina "Estágio Supervisionado 2: Espaços Alternativos" se encaminharam para o projeto de extensão "Revoada Musical" (Universidade Federal de Goiás, 2017b), voltado para a construção do espetáculo Rastros Musicais. Nesse, 35 crianças com idade entre 7 e 12 anos representavam, cantavam e tocavam no instrumental Orff ${ }^{5}$ com acompanhamento pedagógico-musical da professora supervisora, da professora orientadora, dos licenciandos e de duas funcionárias técnico-administrativas. A ação docente coletiva dos estagiários sobre o tema "Orquestra" trouxe a lume a figura de Maria Anna Walburga Ignatia Mozart, Nannerl Mozart (1751-1829), cuja atuação enquanto musicista segue secundarizada pela proeminência do seu irmão, Wolfgang Amadeus Mozart (1756-1791).

Por sua vez, os sete estagiários de "Estágio Supervisionado 5: Espaço Escolar" desenvolveram o projeto de ensino "Chiquinha Gonzaga: Vida e Obra" em aulas de música para uma turma de $3^{\circ}$ do ensino fundamental do Cepae/UFG, sob a supervisão das professoras orientadora e supervisora. ${ }^{6}$

\footnotetext{
3 A referida proposta foi vencedora da oitava edição do Prêmio Professor Rubens Murillo Marques, promovido pela Fundação Carlos Chagas (FCC). Desde 2011, o prêmio busca valorizar e divulgar experiências educativas realizadas por docentes dos cursos de licenciatura na formação de professores para a educação básica.

4 Para maiores informações, bem como para acessar fotos do evento, consultar o site do Cepae (Festival..., 2017).

5 Corresponde a um conjunto de instrumentos musicais concebidos e organizados pelo compositor e pedagogo musical alemão Carl Orff (1895-1982). O instrumental Orff é composto, fundamentalmente, por instrumentos de percussão com altura definida (xilofone baixo, xilofone contralto, xilofone soprano, metalofone baixo, metalofone contralto, metalofone soprano, dentre outros) ou com altura indefinida (pratos, triângulo, reco-reco, clavas, etc.). 6 A autora deste texto foi orientadora nas três disciplinas de estágio da Emac/UFG, sendo que em "Estágio Supervisionado 1: Campos de Estágio e Aspectos Ético-Profissionais" dividiu a função de orientação com a professora Ruth Sara de Oliveira Moreira. A professora de música do Cepae/UFG, Telma de Oliveira Ferreira, desempenhou o papel de professora supervisora em todas as ações da proposta.
} 
As ações docentes semanais realizadas pelos estagiários ao longo de quatro semanas tematizaram a vida e a obra de Francisca Edwiges Neves Gonzaga, mais conhecida como Chiquinha Gonzaga (1847-1935), de modo que as 30 crianças da turma pudessem conhecer o contexto e a vida da musicista, bem como interpretar sua obra "Lua branca", com arranjo construído pelos estagiários, também com a utilização do instrumental Orff.

Conforme se percebe, o tema "Mulheres na Música" foi desenvolvido em três ações formativas com foco na vida e na obra de três musicistas: Rita Lee, Nannerl Mozart e Chiquinha Gonzaga. A escolha por uma epistemologia centrada em produções femininas aconteceu por algumas razões. Tal como mencionado na seção anterior, pensar/agir com o saber musical sensivel pressupõe a tentativa de colocar em tensão aspectos da realidade social comumente percebidos de forma separada e hierarquizada. Em nossa sociedade, além da dissociação, há um nivelamento que valoriza, por exemplo, o intelectivo em detrimento do corporal, a teoria em detrimento da prática, a racionalidade em detrimento da sensibilidade e, também, as produções masculinas em detrimento das femininas. Todas essas dualidades se fazem sentir no campo musical, incluindo a última delas. A preponderância dos construtos masculinos sobre os femininos vem sendo construida historicamente, restando às mulheres espaços marginais de atuação e produção, seja na música de concerto, seja na música popular (Nogueira; Fonseca, 2013).

Ao protagonizá-las, acredita-se estar fazendo frente a uma lógica social que insiste em circunscrever o feminino à condição de submissão e objetificação. Mais ainda, ao trazer à tona uma abordagem feminista como possibilidade de materialização de saberes musicais sensiveis na escola, há a intenção de contribuir para que essa instituição cumpra seu papel de justiça social. Para Fraser (2002, p. 9), justiça social engloba distribuição e reconhecimento, abarcando diversos eixos de subordinação: classe, diferença sexual, raça, etnicidade, sexualidade, religião, nacionalidade, dentre outros.

Segundo Libâneo e Silva (2020, p. 819), “justiça social na escola seria garantir a todos os alunos uma base comum de conhecimentos e competências indispensáveis à preparação para um futuro profissional e obtenção de êxito na vida social". No decorrer do texto, os autores enfatizam que aliada a essa garantia de uma formação cultural e científica comum está a atenção à diferença, ou melhor, o trabalho pedagógico com a diversidade sociocultural. A união entre produções femininas e saberes musicais sensiveis corresponde, justamente, à tentativa de articular redistribuição de saberes com o reconhecimento e valorização das diferenças no ambiente escolar.

Cumpre destacar que a pesquisa empírica junto às atividades da proposta (de planejamento, de execução e de avaliação) foi fundamentada nos pressupostos da etnografia e da pesquisa-ação. A intenção era que professoras orientadoras, professora supervisora e professores em formação pudessem investigar científica e coletivamente as três possibilidades de materialização de saberes musicais sensiveis no contexto escolar (em atividade no contraturno, em projeto de extensão e em disciplina curricular obrigatória), 
com vistas à produção de artigos / relatos de experiência para serem socializados em eventos do campo da educação, da música e/ou da educação musical.

Inicialmente, a etnografia foi importante arcabouço para a imersão, a ambientação e a integração com o cotidiano escolar e seus agentes. Estagiários e professoras orientadoras buscavam perceber a cultura da escola de modo ativo, incorporando-se ao contexto pela via da observação participante (Angrosino, 2009). Além disso, as impressões eram registradas em diários de campo (Oliveira, A., 2013): caderno tipo ata individual em que cada pesquisador anotava elementos da experiência vivida, bem como inseria elementos textuais e audiovisuais (partituras, textos, imagens, links de vídeos/ filmagens).

Quando se iniciavam as ações docentes dos estagiários, os pressupostos e recursos da etnografia iam cedendo lugar para a pesquisa-ação sem, todavia, serem abandonados. Houve uma prevalência da pesquisa-ação colaborativa (Ghedin; Franco, 2011) devido à necessidade de intervenção coletiva, quiçá de transformação, do ambiente escolar. Tendo como sustentáculo essa segunda metodologia, foram construídos os planos de aula reflexivos e as apresentações musicais, bem como conduzidas as ações docentes dos estagiários. Todavia, tanto etnografia quanto pesquisa-ação foram alicerces para as discussões coletivas, as produções escritas individuais - incluindo os relatos de experiência - e as atuações no ambiente escolar.

O uso dos aportes de ambas as abordagens metodológicas tornou possível a coleta, o arquivamento e a análise dos dados das três ações desenvolvidas em campo. A seguir, os resultados aferidos durante a pesquisa de campo junto à proposta "Mulheres na Música" são colocados em articulação com a categoria de saber musical sensivel, com a finalidade de apresentar os avanços e os desafios suscitados por essa articulação no contexto escolar.

\section{SABER MUSICAL SENSÍVEL NA PROPOSTA "MULHERES NA MÚSICA"}

Aliar saber musical sensivel e epistemologias feministas em processos pedagógico-musicais escolares é, no mínimo, desafiador. A decisão por fazê-lo previu tanto dificuldades quanto potencialidades. De todo modo, no decurso da proposta apareceram problemas inesperados. Às vezes encontrávamos soluções criativas para eles; em outras, por faltarem respostas imediatas, os encarávamos como questões a serem elaboradas com mais rigor em etapas futuras. ${ }^{7}$ Isso sem perder de vista a noção fundamental de que as três ações formativas estivessem vinculadas ao ideal de uma escola justa e, enquanto

\footnotetext{
7 A proposta “Mulheres na Música” está, atualmente, na quarta etapa. A primeira teve início em 2016 e evidenciou a contribuição de mulheres musicistas no interior da música sertaneja. A segunda etapa foi implementada em 2017 e corresponde às ações em tela. Na terceira, o foco recaiu sobre a cirandeira pernambucana Lia de Itamaracá (1944-) e aconteceu em 2018. Em 2020 e 2021, a quarta etapa está a tematizar musicistas goianas. Esse alongamento temporal da última etapa se deve, principalmente, à alteração dos calendários escolares pela pandemia do novo coronavírus, que fez com que parte do ano letivo de 2020 se estendesse por 2021.
} 
tal, comprometida com a redistribuição qualificada de saberes musicais sensiveis e com o reconhecimento e valorização de produções femininas no campo musical.

A discussão de resultados feita a seguir tenta evidenciar a tensão entre entraves e possibilidades da proposta, valendo-se da estruturação de saber musical sensível elaborada por Aquino (2018a, 2021). Para isso, foram examinados os dados colhidos nos diários de campo, nos relatos de experiência e nos planos de aula reflexivos elaborados pelos estagiários. ${ }^{8}$ Os planos de aula possuíam a estrutura-padrão (tema, conteúdos, objetivos, metodologias, recursos didáticos, avaliação e bibliografia) acrescida de uma parte em que os estagiários redigiam suas reflexões sobre as ações docentes após serem realizadas.

Reitere-se que a construção da proposta "Mulheres na Música" é fruto de uma parceria colaborativa entre IES e escola campo. Logo, não se pode pensar que os membros da primeira instituição se encaminharam para a segunda visando simplesmente aplicar e testar teorias previamente selecionadas. Em verdade, a estruturação de Aquino (2018a, 2021) não é utilizada com o intuito de enquadrar os processos educativo-musicais escolares, muito mais complexos que qualquer intenção classificatória. O que se espera é que a referida estruturação seja lente de análise capaz de auxiliar a captar como os saberes musicais sensiveis estão sendo operacionalizados na escola, tendo em vista que qualquer exame investigativo é sempre limitado diante da complexidade dos fenômenos escolares.

Conforme detalhado anteriormente, a autora concebe o saber musical sensivel em termos de fundamentos (ético, cognitivo, emocional e somático), dimensões (artística, científica e filosófica) e perspectivas (relações com outros campos do saber escolares). Nomeá-los separadamente é mero recurso didático para viabilizar a análise, tornando-a mais organizada e compreensível. $\mathrm{Na}$ realidade, esses elementos formam entre si uma constelação. Ou seja, embora tratados separadamente, eles compõem um campo de tensão: não há fundamento desvinculado dos demais, tampouco as perspectivas se apartam das dimensões e dos fundamentos. Afinal, reitere-se, separá-los para classificá-los é recurso até certo ponto artificial, pois razão, corpo, moral e sentimentos funcionam em simbiose. Todavia, é algo necessário para reforçar as peculiaridades de cada um deles, bem como para evidenciar a importância em articulá-los em um todo conscientemente integrador.

Quando trata do fundamento ético do saber musical sensivel, Aquino (2018a, 2021) traz para a discussão as categorias de humanização, emancipação e justiça social. Segundo a autora, a educação musical escolar precisa estar comprometida com a humanização e emancipação dos sujeitos escolares, no interior de uma escola justa que garanta a distribuição mais igualitária

\footnotetext{
8 Exemplos de diários de campo, planos de aula reflexivos, relatos de experiência, planos de ensino das disciplinas de estágio, bem como de fotos da sala de música, das ações docentes e das apresentações musicais podem ser colhidos em Aquino (2018a).
} 
dos bens sociais, nos quais se incluem os saberes musicais. Todavia, além da distribuição mencionada pela autora, há que se considerar também o reconhecimento, envolvendo questões relacionadas à diversidade, representação, identidade e diferença (Fraser, 2002; Libâneo; Silva, 2020).

Trazendo a discussão para os meandros das práticas escolares, Aquino (2021, p. 242) afirma que "em cada conteúdo musical trabalhado nas turmas da educação básica, está contida a possibilidade de humanização, embora ela possa não se concretizar". Isso quer dizer que cada conteúdo musical trabalhado em sala de aula contém em si potencialidades mais ou menos humanizadoras, mais ou menos emancipatórias, de maior ou menor vínculo com a luta por justiça social.

No decorrer da proposta "Mulheres na Música", foram vários os conteúdos musicais trabalhados. Uma estagiária da disciplina "Estágio Supervisionado 5: Espaço Escolar" comenta sobre os conteúdos centralizados especificamente no projeto de ensino "Chiquinha Gonzaga: Vida e Obra":

De acordo com o esboço do projeto de ensino, o tema foi a presença feminina de Chiquinha Gonzaga na música brasileira, com os seguintes conteúdos: biografia, obras, o feminino e o masculino, notas musicais, a escrita/grafia/registro musical convencional, a realização/performance musical (Relato de experiência, estagiária A).

A escolha pelos conteúdos, repertórios e práticas musicais foi, quase sempre, tomada coletivamente, envolvendo professoras supervisora e orientadora, estagiários e, em certas ocasiões, as próprias crianças. O trabalho pedagógico-musical teve como norte a formação integral dessas crianças, de forma que pudessem estabelecer conexões de unidades dialéticas historicamente cindidas e hierarquizadas: teoria e prática, corpo e mente, ética e emoção, masculino e feminino. As crianças cantavam, tocavam instrumental Orff, discutiam aspectos da vida e da obra das musicistas, internalizavam conceitos musicais e elaboravam emoções estéticas em articulação com o uso inteligente de seus corpos sonoros.

Além disso, foi possivel verificar que o acesso, a reflexão e a vivência musical em torno de Rita Lee, Nannerl Mozart e Chiquinha Gonzaga significou, de modo amplo, fazer justiça às atuações e às produções de mulheres no campo da música. Nesse tocante, foi notório o afinco de todos os envolvidos com a proposta. Nas palavras de uma estagiária de "Estágio Supervisionado 1: Campos de Estágio e Aspectos Ético-Profissionais":

Trabalhar com a Rita Lee está sendo bem interessante. Nunca parei para pensar com calma como nós [mulheres] somos deixadas de lado. É muito importante trazer a Rita Lee para as crianças, para todos nós. Imagino que as meninas da turma ficarão mais inspiradas a contestar, em [sic] serem protagonistas em qualquer lugar. Outra coisa, nesse estágio eu recebi a ajuda de todos os colegas do estágio, das professoras, da escola 
e da academia. Mesmo com todos os erros e as dificuldades, eu não conseguiria se não tivesse [sic] todos me auxiliando. $\mathrm{Na}$ realidade que nós enfrentamos lá fora, nós estamos sozinhos nessa jornada. Aqui nós nos sentimos seguros por ter o auxílio de colegas e professoras (Diário de campo, estagiária B).

Em que pese a justiça social ter sido contemplada em suas esferas de distribuição e reconhecimento (Fraser, 2002) - por meio de conteúdos musicais que potencializassem o trabalho com saberes sensiveis e repertórios femininos - alguns eixos de subordinação não foram tematizados, como os de identidade de gênero, raça, etnicidade e religião. Problematizar tais eixos segue como desafio para as etapas subsequentes da proposta.

Com relação ao fundamento cognitivo dos saberes musicais sensiveis, Aquino (2018a, 2021) esclarece que os processos de educação musical levados a cabo nas escolas básicas pressupõem a apropriação da(s) cultura(s) musical(is) e o desenvolvimento do modo de operar musical. Este último engloba generalizações conceituais "relativas tanto aos conteúdos dos saberes musicais sensiveis em si quanto às ações mentais correspondentes à forma de constituição desses conteúdos" (Aquino, 2021, p. 247). Isto é, os alunos se apropriam tanto dos conceitos quanto dos procedimentos relacionados à produção desses conceitos.

É possível afirmar que as três ações formativas propiciaram a construção de modos de operar musicais. Professoras, estagiários e crianças arranjaram, improvisaram, cantaram, tocaram, apreciaram e refletiram, consoante os elementos musicais (ritmo, melodia, dinâmica, timbre, etc.) das obras experienciadas. Foram criadas inúmeras e diversificadas situações pedagógicas para a internalização de conceitos musicais, bem como tentativas no sentido de demonstrar os procedimentos utilizados pelas musicistas (performance, composição, arranjo, improvisação, etc.) para produzirem no campo musical. Contudo, não aconteceram atividades relacionadas à composição dos(as) integrantes da proposta. Em ações futuras ligadas ao tema "Mulheres na Música", espera-se fomentar a produção autoral de seus integrantes, especialmente de professoras, estagiárias e meninas.

Também carece de maior atenção o fundamento emocional dos saberes musicais sensiveis. Aquino (2018a, 2021) demonstra que tais saberes possuem relação de interdependência com os sentimentos, a imaginação e a fantasia, destacando que a experiência estética suscita um tipo diferente de emoção: a emoção estética. Ainda segundo a autora, a emoção estética é uma emoção cognitiva, pensante, inventiva: "É por meio do exercício inteligente da fantasia que tal emoção inclina-se a reelaborar cognitivamente as reações emocionais rudimentares, bem como os sentimentos contraditórios provocados pelas obras musicais" (Aquino, 2021, p. 256).

Embora as três ações formativas tenham possibilitado lidar com as emoções estéticas, ou seja, com um pensamento emocional complexo e inventivo, o elemento emocional continuou contingente. Há explicações prováveis para isso: o estudo das emoções é historicamente negligenciado nas culturas ocidentais, 
assim como o é o trabalho pedagógico com as emoções nas práticas escolares. O desafio que ainda se coloca no campo da educação musical escolar é: como trabalhar as emoções estéticas de forma sistemática e em articulação com valores, conceitos e corporeidade nas atividades musicais escolares?

Ressalte-se que durante as três ações houve forte apelo para o exercício inteligente e sensivel do corpo. Aquino (2018a, p. 131) aponta que "a música é feita pelo corpo e para o corpo" e que, por conseguinte, "desenvolver processos pedagógico-musicais em escolas de educação básica que desconsiderem a corporeidade seria o equivalente a extirpar da experiência musical sua concretude". É importante lembrar que, com o advento das metodologias ativas no campo da educação musical no decorrer do século XX, as práticas corporais ganharam posição de destaque. Por isso, mesmo que o corpo permaneça marginalizado nas práticas escolares, na seara específica da educação musical escolar, pode-se supor que sua importância seja diferente.

Tal consideração se confirmou na proposta "Mulheres na Música": eram frequentes atividades de marcha, de movimentação e de elaboração de gestualidades. Professoras e estagiários criaram diversas situações com as crianças para a internalização dos conceitos musicais e a externalização sonora a partir do fundamento somático do saber musical sensível.

Por certo, é possivel inferir que a proposta se empenhou em contemplar os quatro fundamentos, conforme suas especificidades e buscando suas articulações. Cada fundamento foi considerado de acordo com suas idiossincrasias, concretizado em maior ou menor grau, com o propósito de se interpenetrar com os demais, haja vista o desenvolvimento global de professoras, estagiários e crianças.

Sobre as dimensões científica, filosófica e artística, Aquino (2018a, 2021) afirma que o saber musical sensivel se relaciona com os saberes científicos e com os saberes filosóficos por aproximações e distanciamentos, sendo, fundamentalmente, um tipo de saber artístico justamente por este último possuir potencial integrador. Em suas palavras, "a(s) ciência(s) tende(m) a privilegiar a formação de conceitos científicos e a(s) filosofia(s) a de conceitos filosóficos, ambas pela via racional, enquanto a(s) arte(s) tende(m) à interligação dos saberes pelo exercício da não dissociação" (Aquino, 2018a, p. 124).

Durante a proposta, nos momentos que contavam com a presença de todos os integrantes (professoras, estagiários e crianças), notou-se uma prevalência da dimensão artística do saber musical sensivel, pois o trabalho englobava linguagem verbal e não verbal (gestual, sonora, visual), além de contemplar a articulação de conceitos, vivências, teorias, práticas, juízos e emoções. Quando havia reuniões, encontros ou aulas envolvendo apenas as professoras e os estagiários, a educação musical era comumente tomada como ciência, ou seja, como um sistema produtor de um corpo de conhecimentos e de resultados de pesquisa (Souza, 2007).

Nesses momentos, a educação musical também era dimensionada filosoficamente, com ênfase em sua capacidade de fomentar o exercício do pensamento livre e autônomo e impulsionar reflexões sobre as contradições encerradas 
nos processos emancipatórios de (auto)conscientização e (auto)crítica. A esse respeito, um estagiário da disciplina de "Estágio Supervisionado 2: Espaços Alternativos" enfatiza:

Tudo o que fizemos possibilitou, para cada estagiário, uma experiência única, pois percebemos no decorrer das aulas (na escola campo e na universidade) e através das nossas discussões ocorridas ao final de cada ação docente, os nossos pontos fortes e fracos e o que ainda precisamos melhorar, colaborando assim para nosso amadurecimento como professores (Relato de experiência, estagiário C).

As perspectivas, isto é, as interações dos saberes musicais com outros campos do saber, ficaram manifestas: i) na contextualização da vida e da obra das musicistas tematizadas; ii) no planejamento das atividades com os estagiários, que contou com referenciais de diferentes dominios; iii) no trabalho cotidiano com as crianças, que incluía atividades interdisciplinares; iv) nas discussões coletivas, cujos problemas levantados demandavam o uso de diferentes abordagens. De todo modo, há muito a avançar em termos de diálogo estruturado e qualificado entre o saber musical sensivel e outros saberes escolares, especialmente com outras disciplinas tradicionais do currículo das escolas de educação básica.

Em suma, a proposta "Mulheres na Música" representou uma investida na direção de experienciar o saber musical como saber sensivel no cotidiano escolar. Seu êxito foi evidente no tocante à efetivação simultânea de três formas de inserção de saberes musicais sensiveis no contexto escolar, ao reconhecimento e à valorização das produções de mulheres musicistas, à consolidação de práticas colaborativas entre IES e escola de educação básica e ao desenvolvimento conjunto de seus participantes. A consciência das limitações enfrentadas no que tange ao exercício composicional, ao trabalho pedagógico-musical com a emoção estética e às interações estruturadas com outros campos do saber, é fermento para ações continuadas cada vez mais imbuídas em potencializar epistemologias integradoras e progressistas para a educação musical escolar.

\section{APONTAMENTOS FINAIS}

A discussão sobre o saber musical como saber sensivel somada à descrição e análise da proposta formativa "Mulheres na Música" atesta a necessidade de aprofundamento do debate conceitual em torno da(s) epistemologia(s) da educação musical escolar e, também, de reflexões sobre práticas pedagógico-musicais comprometidas com a formação integral dos sujeitos escolares. Na proposta ora evidenciada, houve avanços, dificuldades e pontos de embaraço que, em conjunto, funcionam como fermento para a continuidade das atividades. Afinal, como professores de música somos movidos tanto por êxitos quanto pelos desafios que se apresentam nos processos de ensino e de aprendizagem musical. 
Com base na pesquisa empírica implementada, que se valeu da observação participante, de ações docentes e da análise de produções escritas, pode-se elencar alguns impactos gerais da proposta em seus envolvidos. Em termos institucionais, o fortalecimento da parceira entre universidade e escola de educação básica repercutiu positivamente na formação de professores de música (formadores e em formação) e de crianças. As professoras orientadoras e supervisora se sentiram estimuladas em seus processos de formação continuada e seguem fazendo pesquisas acadêmicas, bem como investigações educacionais voltadas ao aprimoramento de aspectos mais específicos de suas práticas docentes.

Para os estagiários, foi crucial o trabalho de cooperação e a experiência supervisionada com algumas possibilidades - em termos de objetivos, conteúdos, repertórios, metodologias, etc. - de ensino e de aprendizagem da música no contexto escolar. Contudo, um fato precisa ser mencionado: nem todos os professores em formação se engajaram de pronto com a temática "Mulheres na Música". Durante a escolha coletiva por musicistas e repertórios, havia embates frequentes sobre a necessidade de se voltar a repertórios consolidados, leia-se repertórios masculinos. É um dado que merece ser explorado em trabalhos futuros.

Em paralelo a isso, o engajamento das crianças foi notório, assim como de suas famílias, quando requeridas. Os produtos da proposta, especialmente as apresentações musicais, mobilizaram as comunidades escolares que frequentemente lotavam os espaços em que as apresentações públicas aconteciam. Ainda que isso seja um sinal positivo, seria interessante perceber outras formas de eco da proposta em ambas as comunidades escolares (universidade e escola de educação básica). Mais um elemento que pode ser elaborado em análises subsequentes.

Frente ao exposto, uma conclusão é evidente: a proposta reverberou no desenvolvimento conjunto de instituições e pessoas envolvidas. Este artigo veio, justamente, na direção de alavancar pensamentos e ações, conceitos e anseios para ações pedagógico-musicais escolares que impulsionem o desenvolvimento global dos sujeitos, através de epistemologias potencialmente transgressoras dos modos de operar dominantes, que tendem a privilegiar a mente em detrimento do corpo, o masculino às custas do feminino. É nesse sentido que a proposta "Mulheres na Música" pretende prosseguir: com novas ações formativas capazes de colocar em xeque as hierarquias historicamente constituídas, incrementando saberes musicais sensiveis e produções de mulheres musicistas nos contextos escolares.

Pós-escrito: Uma versão inicial deste texto foi elaborada 45 dias antes da interrupção do funcionamento de escolas e instituições de ensino superior devido à pandemia causada pelo novo coronavírus. A versão enviada para esta revista se consolidou em agosto de 2020 e a escrita final, em fevereiro de 2021. Durante a pandemia, instituições educativas pararam de funcionar e/ou optaram por ofertar educação a distância e/ou adotaram modelos mistos. A proposta "Mulheres na Música" ficou temporariamente suspensa entre 
março e agosto de 2020 e retornou em setembro do mesmo ano sob o formato de ensino remoto emergencial. Diante de tantas incertezas, irrompem inúmeros questionamentos: aulas online são pertinentes para a consecução de propostas pedagógico-musicais coletivas, envolvendo professoras, estagiários e crianças? As plataformas digitais têm condições de promover abordagens em educação musical escolar comprometidas com a luta por justiça social em termos de redistribuição e reconhecimento? Será possivel trabalhar com saberes musicais sensiveis junto às escolas de educação básica por meio das novas tecnologias? Espera-se, em próximos trabalhos, refletir sobre essas e outras questões, fazendo com que as práticas relacionadas à formação de professores de música e à educação musical escolar permaneçam intrinsicamente conectadas às problemáticas da sociedade contemporânea.

\section{REFERENCIAS}

ANDRAUS, Gisele Crosara. Um olhar sobre o ensino de música em Uberlândia (MG). Revista da Abem, Porto Alegre, v. 16, n. 19, p. 65-73, mar. 2008.

ANGROSINO, Michael. Etnografia e observação participante. Porto Alegre: Bookman, 2009.

AQUINO, Thaís Lobosque. Saber musical sensivel nas escolas de educação básica brasileiras: perspectivas, dimensões e fundamentos. Revista SulAmericana de Filosofia e Educação, Brasília, n. 29, p. 116-136, nov. 2017/ abr. 2018a.

Música, estágio e pesquisa: ações formativas com o tema Mulheres na Música. Textos FCC, São Paulo, v. 55, p. 79-145, nov. 2018b. Disponível em: http://publicacoes.fcc.org.br/index.php/textosfcc/article/view/6157. Acesso em: 27 jan. 2021.

O racismo contra o negro no Brasil: o que pode fazer a educação musical escolar?. Revista Fladem Brasil, [s. l.], ano 1, n. 1, p. 32-48, jan. 2020.

Epistemologia da educação musical escolar: um estudo sobre os saberes musicais nas escolas de educação básica brasileiras. Goiânia: Editora da UFG, 2021.

BEINEKE, Viviane. Ensino musical criativo em atividades de composição na escola básica. Revista da Abem, Londrina, v. 23, n. 34, p. 42-57, jan./jul. 2015.

BRASIL. Lei $n^{\circ} 9.394$ de 20 de dezembro de 1996. Estabelece as diretrizes e bases da educação nacional. Brasília: Presidência da República, 1996. Disponivel em: http://www.planalto.gov.br/ccivil_03/leis/19394.htm. Acesso em: 13 ago. 2020. 
BRASIL. Lei $n^{\circ} 11.769$, de 18 de agosto de 2008. Altera a Lei $n^{\circ} 9.394$, de 20 de dezembro de 1996, Lei de Diretrizes e Bases da Educação, para dispor sobre a obrigatoriedade do ensino da música na educação básica. Brasília: Presidência da República, 2008. Disponivel em: https://www.planalto.gov. br/ccivil_03/_ato2007-2010/2008/lei/111769.htm. Acesso em: 13 ago. 2020.

BRASIL. Lei $n^{\circ} 13.278$, de 2 de maio de 2016. Altera o $\S 6^{\circ}$ do art. 26 da Lei $\mathrm{n}^{\circ}$ 9.394, de 20 de dezembro de 1996, que fixa as diretrizes e bases da educação nacional, referente ao ensino da arte. Brasília: Presidência da República, 2016. Disponível em: https://www.planalto.gov.br/ccivil_03/_ ato2015-2018/2016/lei/113278.htm. Acesso em: 13 ago. 2020.

DUARTE JÚNIOR, João Francisco. O sentido dos sentidos: a educação (do) sensivel. 2000. Tese (Doutorado em Educação) - Faculdade de Educação, Universidade Estadual de Campinas, Campinas, 2000.

FESTIVAL Bem-Te-Fiz (2017). In: CEPAE. Goiânia: Universidade Federal de Goiás, Centro de Ensino e Pesquisa Aplicada à Educação, 2017. Disponível em: http:/ /www.cepae.ufg.br/p/19705-festivalbem-te-fiz-2017. Acesso em: 14 ago. 2020.

FRASER, Nancy. A justiça social na globalização: Redistribuição, reconhecimento e participação. Revista Crítica de Ciências Sociais, Coimbra, n. 63 , p. 7-20, out. 2002.

GHEDIN, Evandro; FRANCO, Maria Amélia Santoro. Questões de método na construção da pesquisa em educação. 2. ed. São Paulo: Cortez, 2011.

LEE, Rita. Rita Lee: uma autobiografia. São Paulo: Globo, 2016.

LIBÂNEO, José Carlos; SILVA, Eliane. Finalidades educativas escolares e escola socialmente justa: a abordagem da diversidade social e cultural. RPGE: Revista on-line de Política e Gestão Educacional, Araraquara, v. 24, n. esp. 1, p. 816-840, ago. 2020.

MARQUES, Wladimir de Oliveira. "Batuque é um privilégio. Ninguém aprende samba no colégio." Será?: interfaces entre a escolarização e a práxis musical de ritmistas do Grêmio Recreativo Escola de Samba Império Serrano. 2019. Dissertação (Mestrado) - Faculdade de Educação, Universidade Federal do Rio de Janeiro, Rio de Janeiro, 2019.

NEVES, Marcelo Saldanha das. Cantando povos indígenas e não sobre povos indigenas: Uma experiência com Música Indígena em sala de aula. Revista Fladem Brasil, [s. l.], ano 1, n. 1, p. 49-58, jan. 2020.

NOGUEIRA, Isabel Porto; FONSECA, Susan Santos (org.). Estudo de gênero, corpo e música: abordagens metodológicas. Goiânia: ANPPOM, 2013. (Série Pesquisa em Música no Brasil). 
OLIVEIRA, Amurabi. Algumas pistas (e armadilhas) na utilização da etnografia na educação. Revista Educação em Foco, Juiz de Fora, v. 16, n. 22, p. 163-183, dez. 2013.

OLIVEIRA, Ana Angélica Rodrigues de. A música popular brasileira (MPB) na escola: uma análise sobre a sua contribuição para uma educação emancipatória na rede pública de ensino de Barra Mansa/RJ. 2019. Tese (Doutorado em Educação) - Faculdade de Educação, Universidade Federal do Rio de Janeiro, Rio de Janeiro, 2019.

SEBBEN, Egon Eduardo; SUBTIL, Maria José. Concepções de adolescentes de $8^{a}$ série sobre música: possíveis implicações para a implementação das práticas musicais na escola. Revista da Abem, Porto Alegre, v. 18, n. 23, p. 48-57, mar. 2010.

SOUZA, Jusamara V. Pensar a educação musical como ciência: a participação da ABEM na construção da área. Revista da Abem, Porto Alegre, v. 15, n. 16, p. 25-30, mar. 2007.

UNIVERSIDADE FEDERAL DE GOIÁS. Ação de extensão: evento: Festival Bem-Te-Fiz. Goiânia: UFG/Cepae/Emac, 2017a.

UNIVERSIDADE FEDERAL DE GOIÁS. Ação de extensão: projeto: Revoada Musical. Goiânia: UFG/Cepae/Emac, 2017b.

VIEIRA, Djenane. O RAP como recurso de musicalização e reflexão sobre educação étnico-racial na escola regular. Revista Fladem Brasil, [s. l.], ano 1, n. 1 , p. 59-72, jan. 2020 .

WOLFFENBÜTTEL, Cristina Rolim. A inserção da música no projeto político pedagógico: o caso da Rede Municipal de Ensino de Porto Alegre/RS. Revista da Abem, Porto Alegre, v. 18, n. 24, p. 73-80, set. 2010. 
Thaís Lobosque Aquino é doutora em Educação pela Universidade Federal do Rio de Janeiro (UFRJ). Possui mestrado em Música e em Educação, ambos pela Universidade Federal de Goiás (UFG). É especialista em Formação de Professores pela Pontifícia Universidade Católica de Goiás (PUC-GO) e graduada em Educação Musical - Licenciatura em piano (UFG) e em Pedagogia (PUC-GO). Atualmente, é professora adjunta na Escola de Música e Artes Cênicas (Emac/UFG), onde lidera o grupo de pesquisa Músicas e Processos Formativos (MusiProf). Desenvolve investigações nas áreas de educação e música focalizando os seguintes temas: educação musical; formação de professores; teoria crítica e educação; epistemologia da educação musical escolar; e mulheres na música. Suas produções incluem artigos em revistas especializadas, em anais de eventos científicos, capítulos de livros e livro. É vencedora da oitava edição do Prêmio Professor Rubens Murillo Marques da Fundação Carlos Chagas (FCC) e atual Representante Estadual (Goiás) da Associação Brasileira de Educação Musical (Abem). https://orcid.org/0000-0002-9767-8509 